\title{
Crossing Borders and Borderlands: Childhood's Secret Undergrounds
}

Sonja Arndt, University of Waikato

Marek Tesar, University of Auckland

\begin{abstract}
This chapter examines childhood undergrounds as subversive spaces that respond to children's borderlands and border crossings. Centred on a tale of two childhoods, it analyses children's secret coping practices within very different socio-political contexts and realities. One story is of a boy growing up in communist Czechoslovakia in the 1970s and 1980s, and his relationship to the borderlands between his country and Austria. The other is about a girl born into a German community in Australia, and her linguistic and cultural border crossings. The impact of their borders and border crossing strategies are theorised in relation to children's ideological settings and forming subjectivities, to offer fresh understandings of childhood border experiences.
\end{abstract}

\section{Childhood border zones}

Childhoods are curious and inaccessible to adults. This chapter problematises children's relationships with borders by exploring childhood undergrounds as subversive spaces that respond to borderlands and border crossings in children's lives. It is centred on a tale of two childhoods, through which we examine the significance of children's private border crossing practices embedded within the social and political contexts of their everyday realities. These childhoods are different from each other, however they connect through the children's experiences of the anxieties and excitements evoked in response to the 
borders in their lives. They tell a story of the complexity of navigating borders and living in borderlands, and experiencing both real physical borders as well as imaginary ones. One of the childhoods investigated is the story of a boy growing up in communist Czechoslovakia in the 1970s and 1980s, and his relationship to the borderlands separating his country from neighbouring Austria. This physical border could not be crossed: the land on which the boy looked out every day was a forbidden space, blocked by barbed wire, and guarded by soldiers. The boy and other children around him developed a childhood underground, in which they discovered their own ways to cross the borders to this forbidden land: through their private stories and secret games. The other childhood borders that we analyse are of a girl born into a German community in Australia, and her culturally mediated border crossings. Her dualistic childhood entangled her in a daily migration between the linguistic and cultural Germanness of her home and wider family, and her Australian early education and local encounters. The borderlands with which she and other children of immigrant German families grappled highlight the social, historical and political complexities of their otherness. The interplay of this girl's dichotomous reality challenged her forming self as a foreigner in her own country, and led to a secret relationship with the borders she crossed between her private home and public Australian life. The private experiences, stories and games that form childhood undergrounds are analysed to illustrate the relationship between children and the borders they cross.

\section{Childhood undergrounds and secrets}

The notion of childhood as a distinct experience is signified amongst other things by children's play and subversion as a way of tackling everyday real and metaphorical 
border crossings. This notion is evident within various ideological settings, leading researchers' interests in childhood cultures across continents, cultures and ideologies (Christensen \& James, 2008; James \& Prout, 1997; Jenkins, 1993). The seminal research that underpins this chapter relates to childhoods and undergrounds (Knapp \& Knapp, 1976; Tucker, 1995), and to the argument that many forms of secrets permeate childhoods and children's lives (Van Manen \& Levering, 1996). Similar studies point to the importance of childhoods and their secrets as private engagements and confrontations with children's lives (Haynes, 2005; Sturm, 2008), peer cultures and subcultures (Corsaro, 2005). Secret stories of childhood undergrounds within different borderlands can therefore be seen as having a subversive power that allows children to contest the everyday realities of dominant discourses (Zipes, 2006). Such secret spaces are integral to the lives of the two stories of childhoods through which we analyse children's relationships with physical and cultural borders.

In problematising the multiple real and imaginary borders in these childhoods, we examine the relationships between children and borders within the complex ideological settings in which they are situated. To theorise the impact of these borders and children's border crossing strategies on children's subjectivities, we juxtapose the philosophies of Havel (1985) and Kristeva (1991), to provoke a philosophical re-conceptualisation of child-subjects. This re-conceptualisation is grounded in the production of children as particular subjects as a result of their encounters with and subversion of social and political borders. Both Havel and Kristeva, two European scholars, engage with ideas about foreigners and living with, and traversing borders and borderlands, both in a 
metaphorical and a real sense. They conceptualise living with the unknown, struggling with opposites, dangers and excitements. Both are concerned with otherness, the other, other lands, other experiences. Their work has, however, rarely been used with children and childhoods, provoking the contribution that we attempt to make with this theorisation of childhood border experiences, explicated and analysed through the stories of a boy and a girl.

\section{Powerful and Visceral Borders}

The boy grew up in communist Czechoslovakia in the 1970s and 1980s, right next to the Austrian border. Throughout his childhood there was a strong attraction to the unknown, to what lay behind the barbed wire fence, to the children that lived there and to what they played on the other side of the Danube River. One encounter with these borders was particularly influential. Just before the boy turned six, in the early 1980s, his family had been given permission to leave the country for a two week holiday to experience the sea in Yugoslavia. They were allowed to leave the country only on account of his brother's and his own respiratory problems that had been deliberately exaggerated by sympathetic doctors. A stay by the sea was strongly recommended, as it would be beneficial for their health. Without this recommendation, getting an exit visa from Czechoslovakia was nearly impossible. It was the boy's first visit to Yugoslavia and the first time he was to see the sea, as Czechoslovakia was a landlocked country. While driving in the car to the border, he remembered the stories that children had shared in the playground about the sea - how it looks, how it feels, how it tastes and what games can be played in it. However, as his family was crossing the border, a special unit of the border patrol 
intercepted them and searched their car, their luggage, and themselves. Their entire car, their suitcases, everything, was taken apart. The moment the boy has never forgotten is when they took his little plastic children's suitcase, in which he had toys and various little items that he treasured. The woman who took his plastic suitcase was tall, with short blond hair and a green uniform. She got hold of the boy's suitcase, despite him not wanting to let it go. She grabbed it, opened it, and turned it upside down. The boy's toys fell on the examination table and subsequently to the ground. Some of them broke, and others were taken apart by the examiners. This was an unforgettable moment, and caused the boy to be scared of the person whom his teachers and authorities had taught him to trust.

\section{Imaginary and Painful Borders}

The girl grew up in Australia living out ordinary childhood dreams, games and desires, surrounded by her extended family and close community. Her known private realm involved ordinary familiar experiences, familiar people, familiar rituals, and their strong, familiar Swabian dialect of the German language. Stability and familiar homeliness were particularly important to the German community that the girl's extended family was so closely involved in. They had been involuntarily exiled from their beloved homes in the German settlements in Palestine, crossing painful physical and emotional borders, not by choice, but out of necessity, and eventually finding safe passage to Melbourne, Australia, in 1949 (Hornung, 2005; Tietz, 2009). While the girl knew little of the gravity of such exile, the closeness of her private spaces, purposely familiar, as the community created its place in the new country, nevertheless powerfully impacted her surroundings, and the 
borders she encountered. For her there appeared to be no reason to move beyond this familiar, private realm, to a public place of unfamiliarity and struggle. The trauma of alienation began when she attended the kindergarten at the local university. She was exiled, unnecessarily and incomprehensibly, removed from her private, familiar home community, in an experience resembling, on a smaller scale, her parents' earlier exile. Misunderstandings or non-understandings became the norm. Tide-like, the girl's consciousness ebbed and flowed back and forth in the privacy of her mind, between a solitary sense of comfort within herself, observing kindergarten life from a distance, and what surely were expected by the teachers to be 'fun' activities with the other children, during which she could neither speak nor understand the language. She imagined borders everywhere. The perceived barriers turned her inner tide, towards that private space of safety, overtly demonstrated as withdrawal and non-participation. The girl's private loneliness was invisible and inaccessible to the teachers. She had no inclination to reveal, or to escape it: it was a secure, reliable sense of her space and place, reserved for and accessed only by herself.

School was a similarly uncomfortable disruption in the girl's life. Overtly, it was another physical border crossing from the security and comfort of her private life, into the wider public community, a familiar process for many children the world over. This new border crossing further manifested her perception of herself as alien. Although she quickly mastered such culturally hegemonising tools as the dominant English language, appropriate study skills and local cultural mannerisms, she was and remained classified as 'German'. In her private experience she was just 'normal', living with 'normal' people 
whom she loved and was comfortable with. However, in her private normality she had never been called a 'Nazi', nor been sneered at and insulted for being 'German'. That occurred only when she crossed the borders every day, to school. Perplexed, the teasing at school led the girl further into her own tide of confusion and recession. In the girl's family nobody spoke of being 'German', or of why they lived in Australia. The ravages of war and forced exile were topics that were kept very hidden from the children - and were mostly avoided even amongst adults, as infinitely too raw and painful. It was a number of years before she would find out (through 'social studies' classes focused heavily on German atrocities committed and endured during World War II) what the term Nazi meant, and many more years before she grasped the implications for other children's families, and how they perpetuated certain conceptions of Germanness.

In this developing British colony, all children at the girl's primary school in the 1970s were either immigrants themselves, or direct descendants of immigrants. They were just as foreign as she was, and yet they highlighted that there was a difference. The girl was the alien, the baddy, the foreigner amongst foreigners, the stranger stranger. One girl, from Pakistan, became her friend. To the other children, the girl remained the detested other.

\section{Borders as Subversive Spaces: The boy}

The boy and other children living in close proximity to the borders with West Germany and Austria were able to watch broadcasts of German-speaking television networks. This 
happened in secret; as their physical proximity to the borders and borderlands allowed citizens to pick up the signal. The foreign stories contradicted the messages passed on in their schools and on local television channels, and produced children's cultures based on their own secrets, immersed in their play that was hidden from adults. Childhood undergrounds were formed on the basis of these stories, contesting the public image of expected childhoods, protected and removed from 'adult' notions of borders. In the 1980s the boy was one of the children that was fascinated with the stories that he could watch on Western television. American series, dubbed in German, may have been considered in the West to be mainstream pop-culture kitsch. However, for the boy, cartoons such as Batman and Tom and Jerry were something extraordinary.

In the boy's childhood underground, the most powerful story was Knight Rider, a modern fairy tale of a hero who had a car that could talk, think and drive without a driver. The story was screened every day during the school week, between 18.30 and 19.15, and at these times all the children that the boy knew, his friends, were at home watching it. Children made up and shared stories about Knight Rider, and every child who did not know how or where to watch it was either 'educated', if he or she could be trusted, and accepted into the group, or left out. Adults, and particularly teachers, as the guardians of knowledge and borders, were excluded from this story and from the associated games and conversations. Knight Rider was the children's secret in the borderlands of the playground. Children secretly passed on information about where and how to watch it amongst themselves. The children had developed their own language, based on stories from Knight Rider, as it was aired in German, a language that none of the children spoke. 
They used words and sentences picked up from the television series, which they interpreted and created to make their own meaning, and to develop their own play. For example, the children did not refer to this series by its name (which they were actually unaware of), but they referred to it only as Kit, the name of the car. This experience produced the boy and his friends as children with their own secret play, and their own discourse involving themes and language that contested the public spaces of kindergartens and schools, where different, smooth, official ideological language was used. This was the boy's own childhood underground, where children shared their stories and experiences based on the story of Kit. The teachers could not understand why the children talked to their wrists, and simultaneously moved toy cars, communicating with each other in pseudo-German as they acted out, re-created and developed new scenes from Kit. This experience demonstrates the productive power of resistant childhood discourses, and how such discourses produce childhood subjectivities. Acting outside of the public discourse was a rebellious act, and the children's secrets held this underground together. These undergrounds would not have existed without the close proximity of the border to the West.

For the boy and his friends, there was nothing ordinary about the stories that they encountered on Western television channels, living as close as they did to the borderlands. They found the scenery of the stories from across the border, the actions, the clothes, and the language absolutely fascinating. However, for the children, the major attraction was the car, Kit. Not one of them had ever seen a car like that, as the vast majority of cars on the streets were of Eastern Bloc provenance, such as Škoda, Lada, 
Trabant and Wartburg. Cars from the West were an exception that children rarely spotted and only talked about amongst themselves. This experience provided the children with a visual image of Kit, the modern, beautiful, dark car that could talk, jump and think. From then onwards all the cars on the streets became even more ordinary, and the image of the border, and of the world behind it, became even stronger and more exciting. The border was both magical and painful; the border was foreign; the border was extraordinary; and the crossing happened at the same time every evening.

The boy not only accessed, but also produced his secret stories within his private childhood discourses, without adults. These underground stories were the subject of debates amongst children during recess in schools, in the outreach corner of the playground, and discussed during lunch breaks. They produced different childhood subjectivities to those initiated in the dominant public spaces, and heightened the tension between public and private childhood subject positions. Stories like Knight Rider shaped the boy's childhood and his way of thinking, playing and daydreaming. They also threatened the boundaries between the public and private discourses. These stories and the games they invoked pushed the boundaries of the private into the public space, disturbing and contesting the hegemony of the everyday childhood reality of totalitarian Czechoslovakia. For the boy, the secrets were an essential part of his underground, and of living by the forbidden borders.

Forbidden borders delineated the boy's childhood underground, also for example through secret 'jokes', whose humour contested adults'/teachers' governance of childhoods. 
Children were protective of such jokes, as they sensed how sensitive, inappropriate, and naughty they could be, and that they could possibly even be dangerous. The children were bound to share them in secrecy, and to keep them as a secret and, in their shared underground, that made the children feel special. Aware of the possibility of getting into trouble by sharing them, the children avoided the teachers, as they shared the jokes, and if any teachers came close to them, they stopped talking. They were always aware of the danger, of crossing the private underground borders into the public arena. This negotiation of border crossing was as difficult as the crossing by adults through the borders to the West. Children tried hard to keep the jokes within their childhood underground, and wished that they could cross the physical borders to the countries that contained such amazing stories.

\section{Borders as Subversive Spaces: The girl}

The girl carried many of her borders within herself, crossing and re-crossing them, backwards and forwards, tangentially, seeking to understand their intersections with the adult world, the public world of her peers, and herself. How could she be so labeled? How were the adults whom she trusted and loved so much not able to confront and talk to her about these names? The girl was forced to remain in her unconscious, confused battle with the cultural borders of strangeness, by her inability to approach her trusted adults about her unease. Even the German lessons that she attended every Saturday with the other children of her community provided little relief. The borders remained impossible to clarify, even for her teachers. Of course the girl knew little of the adults' pain, or of their unfinished grappling with their own border crossings and heartaches (Hornung, 
2005). It became clear that she must straddle her cultural borders alone, navigating boundaries that she could not reveal, locked into a solitary, resistant childhood engagement, which invisibly produced her as a child foreigner.

The girl attempted to subvert the impact of her imaginary borders that separated her from the other children. Every day just before the lunch break she snuck out to deposit her sandwiches into a rubbish bin: not because she did not like them, but they were made of brown bread, the kind that defined her as German. Relieved of yet another piece of evidence, the girl proceeded into the lunch break, less apprehensive, hopeful that perhaps the ladies at the tuck shop would again let her have some lollies, which would see her through the day. Keeping this secret from her parents, the girl felt powerful, in the moment, as if she had some control over her situation. If she could hide the evidence, perhaps her peers would forget about her differences and treat her the same, as one of them. Similarly, when the head mistress invited her into her office so that the girl could teach her some German, the girl mistook what was perhaps intended as an attempt to affirm and support her second language knowledge, as another reinforcement of her Germanness. It only exacerbated her alienation, and forced her to cross yet another border, secretly, into that office without being seen. By attempting to dispose of her otherness, she tried to reduce the name calling, even if just for a moment. And if she would repeat the procedure every day, perhaps she could eliminate the ostracism all together? The girl's secrets, in this daily turmoil of the private/public, German/Australian borderlands, were her private, intimate underground. 


\section{Childhood Foreigners}

These stories of childhoods about border crossings illustrate how childhood navigations of borders can be invisible. The imaginary and the actual physical borders existed in the children's everyday crossings from private life to public, traversing the shifts between home and kindergarten, school and community. The stories explicate inner private borders that transgress, and arise from, the openly visible, obvious borders. The borders existed in these children's minds, and needed to be dealt with in childhood realms that remained secluded from the adult world. The boy's and the girl's border crossings highlight the invisibility of childhood struggles with shifts concerning their daily citizenship, not in a legal sense, but as a part of the precarious task of their existence within their everyday world (Dunne, 2006).

Kristeva (1991) narrates and examines the realities of adult foreigners and their experiences of their own foreignness. Her theoretical, philosophical insights are used here to illustrate the raw sensitivities that are implicated in being foreign, and to highlight the non-linear unpredictability of foreigner responses and reactions to their experiences. Through a Kristevan lens the children in these stories can be conceptualized as foreigners, not only genealogically, or in terms of citizenship, but within themselves through the internal border crossings in their personal ontology of themselves and their lives: as foreigners to themselves. Such a recognition perhaps situates children ahead of their time, as Kristeva goes as far as to suggest that recognising the internal foreigner in each individual may, on a hopefully utopian level, lead us to stop detesting the foreignness in others. Had the other children in the Australian school recognized themselves as equally 
strange as the girl in the story, as foreigners themselves, the story perhaps would have been different. Conversely, had the boy and his friends not experienced themselves as foreign to Kit, the elements that they found exotic and exciting may have remained absent and un-noticed. Kristeva (1991) helps us to understand the realm of these two children's stories, through her narration of foreigners' experiences. She writes of them burning variously with rejoicing, and also with destruction, glowing both with fear and with delight, at the memories of their lives, physically left behind, but real in their minds. Kristeva's foreigners are taunted by memories of excessive happiness as well as excessive disaster. They live their lives amongst, between and across borders, in the borderlands of loss and displacement. In our children's stories, their genealogies are personal manifestations of their families' and societies' histories and localized social and political contexts (MacEinri, 1994; Mohanty, 2003), from which the adults sought to protect them. Such protection reinforces a common conceptualisation of childhoods not as realms of foreignness and border crossing, but rather of innocence, to be protected at all costs, up to the onset of adulthood (Dunne, 2006).

Whether they are seen as foreigners alienated within their world, or as innocents in need of protection, considering children as an ideologically or geographically bound group, as in the Greek notion of the polis (Peters \& Marshall, 1996), implicates them in a sense of responsibility, in community with and for the other (Todd, 2004). This conceptually and socially locates the children's border crossing in our two stories. For the boy and the girl, their community consisted, as it does for many children in the world, in acts of familiar everyday activities and engagements. As such, children can be seen simultaneously as 
consumers internalizing their surroundings, and also as active contributors to and producers of their present and their future. Havel (1985) affirms this notion in his observation that citizens are both victims and supporters of the ideological system within which they are situated, of their environment, and of their lives surrounded and bound by borders. He emphasizes the complex power relations within ideological systems where it is unclear who is powerful and who is powerless. Children living amongst borders, either real or imaginary, become powerful through their stories, through their experiences, of resistance and of their childhood undergrounds. The boy's and the girl's power and influence in the wider polis may evade the adult gaze, but, as this Havelian lens highlights, they are nevertheless strongly implicated and contributing to their place within it, and constructing its future. While children and adults had very diverse experiences of borders and borderlands in everyday life, they nevertheless shared the complexities and were governed by the same hegemonic discourses.

Life is a maze of unstable border zones (MacEinri, 1994; Mohanty, 2003; Rose, 1995). On the one hand, the boy's and the girl's home life could be imagined, and broadly classified, as German, for the girl, or through the story of the Knight Rider, for the boy, in response to the power of their daily border crossing. In themselves such classifications would have little meaning. The relevance and power of borders becomes meaningful only in their interplay with the wider, complex elements of every child's encounters with their context, in time, space and place (Rose, 1995). Borderlands, therefore, are messy and dangerous, and create constant tensions. For Havel (1989), borders are everywhere in the life of a child. There are physical and visceral, often mismatched borders representing an 
artificial, brutal cut into a child's familiar everyday perceptions. These borders surround the child, and can be perceived metaphorically. Still, the child struggles with them, and with what they might mean.

Kristeva's (1991) narration of foreigners' happiness traverses similar boundaries and highlights the temporary states of in-between, in which the children sit in their struggles and subversive border crossing. She likens the constant struggles and subversion to a feeling, like fire, flaring unpredictably, resting fleetingly, then racing on, bypassing what the children long for: perhaps familiarity and acceptance, for the girl, or greater access to the forbidden borders, for the boy. Through Kristeva's lens, the girl and the boy, conceptualized as foreigners, could be seen as questioning, all the while, their own strength in the face of difficulty, as they outwardly rise above rejection. Strangely drawn to the inaccessible, this strength elevates the children to a curious happiness, in their personal unsettled discomfort and inner homelessness. On the other hand, as melancholic lovers of their secure home, Kristeva's foreigners, and these two children, long for a melting of the borders, mourn what they see as an inaccessible paradise, irretrievable and out of reach. In some ways, the children blame themselves, also like Kristeva's foreigners, in a certain rage and torment, for both their foreignness and their depression, for their alienation and for being caught on the wrong side of the border, wondering whether or not they are really at fault. Masking their own realities, hiding behind foreign languages, these children too may be neither totally true nor completely false, in the dichotomous power dynamics of their situations. For Kristeva's foreigners, newfound experiences of freedom and resettling, alongside the depressions, deepen their vision and 
insights. And similarly, these children sense truths and revelations about their

communities, which the adults fail to see. By recognising their foreignness, and retreating into their secret childhood undergrounds, they can elevate themselves to new and previously unattainable heights of loose, unfettered freedom, with their own profound and visionary insights.

Passionate and intense, the children then are, in Kristeva's (1991) sense, foreigners, that can take root, cross borders, and attach themselves to a new 'home', a new destination, new ideas, new games, even temporarily. Confused and consumed, children in borderlands become a fusion of the old and the new, freed of everything, but deprived as well, haunted both by their origin and by their destiny, incomplete and complete, both at the same time.

\section{Homelands and Borderzones}

For the boy and the girl a notion of home, as the familiar place of growing up, of belonging, of meanings and memories, contextualizes their borders. Home can be seen as sometimes fixed in time and place, and, at other times, detached, embroiled in constant change and transformation (Silva, 2009; Wise, 2000). Either way, it is a well of comfort, the deeply personal and intrinsic sense, from which these stories spring. The notion of home becomes transformed, as do the children, by the border zones, their responses to them, and the context.

The boy's and the girl's border crossing stories trouble the notion of home. Seen as historically determined, home is a rightful place where one is allowed to be, accepted, 
and non-alien, (Silva, 2009). The boy's and the girl's stories affirm this notion, of nonforeign, in-alien belonging within ones' own home, and within the known and familiar rituals, handed down over generations and adapted to fit the current situations. Their homes entangle a complex archive of histories, rituals, exile and memories, strengthened through experiences shared by children and adults. Their homes and the borders by which these children are surrounded, embody obligations, responsibilities and commitments. Publicly and privately, the children's families and communities, and their uprooting journeys into the unknown at once embroil, produce and harbour their secret childhood undergrounds (Hornung, 2009; Tietz, 2009).

The boy's and the girl's stories illustrate multiple borders that existed as realities in their minds, despite their physical manageability or apparent non-existence. They draw on home as both a physical and non-physical, external and internal concept, bringing 'order out of chaos, a space of comfort amidst fear' (Wise, 2000, p. 295). Outside the home, confronted with their daily borders, the children were immersed in an increasingly tumultuous, globalized, post border world, crossing into states of contradiction and disorienting voices, speaking to them simultaneously (Swanson, 2010). Kristeva's foreigners also struggle with such a polyphony of voices, and their non-linear, tearing confusion of border zones can be related to those ruminating within the children, crossing borders and living in their own borderlands. The border crossing childhoods in these stories highlight the chaos and struggles of navigating the borderzones of home in the wider social and educational spaces in which they are situated. The children inhabit multiple physical and metaphorical spaces, non-aliens within the privacy of their homes, and foreign, yet also not foreign, in public. They cannot escape the public polis. Keeping 
secrets from adults, as the boy and the girl did, is a childhood secret flexing that enables the often messy and dangerous border crossings within childhood undergrounds (Van Manen \& Levering, 1996).

\section{Concluding comments}

Children are formed as part of the systems by which borders are created, whilst at the same time they become the subjects who must subvert those systems to cope with the limitations they create. This analysis has focused on secret strategies and desires, through which children confront and transcend the private borders they encounter within publicly approved childhood spaces. Havel's argument that all citizens are subjected to and at the same time responsible for their context and Kristeva's critical illustrations of experiences of foreignness, have highlighted the uneasy alliance between citizens and borders. Both stress the collective involvement of all citizens in the formation of their polis, Havel through the notion that all citizens are powerful in its creation, and Kristeva in her argument that all citizens are, in the end, foreigners, even within their own context, and within themselves. This chapter uses Havel's and Kristeva's conceptions to stress the significance (and chaos) of children's complex private undergrounds as mechanisms for dealing with evolving, dissolving and reforming borders and borderlands. Its explications offer fresh understandings of children's constantly forming, transforming, border crossing selves, and highlight that these can occur under any social, political or ideological umbrella.

\section{References}


Christensen P. H., \& James A. (eds.). (2008) Research with children: Perspectives and practices (New York, NY: Routledge).

Corsaro W. (2005) The sociology of childhood(London, United Kingdom: Sage).

Dunne J. (2006) 'Childhood and citizenship: A conversation across modernity’,European Early Childhood Education Research Journal, 14(1), 5-19.

Havel V. (1985) 'The Power of the Powerless' in J. Keane (ed.) The Power of the Powerless: Citizens against the State in Central - Eastern Europe(London, United Kingdom: Hutchinson).

Havel V. (1989) Living in truth: Twenty-two essays published on the occasion of the award of the Erasmus prize to Václav Havel (London, United Kingdom: Faber and Faber).

Haynes J. (2005) 'Secrets and boundaries in classroom dialogues with children: From critical episode to social enquiry', Childhood and Philosophy, 1(2), www.filoeduc.org/childphilo.

Hornung P. (2005) 'Forword' in P. Hornung \& H. Arndt (eds.) Memories of Palestine: Narratives about life in the Templer communities 1869-1948 (Melbourne, Australia: Temple Society Australia Heritage Group).

Hornung P. (2009) 'From Palestine to Cyprus' in H. Blaich (ed.) Exiled from the Holy Land (Melbourne, Australia: Temple Society Australia Heritage Group).

James A., \& Prout A. (eds.) (1997) Constructing and reconstructing childhood: Contemporary issues in the sociological study of childhood (London, United Kingdom: Falmer Press). 
Jenkins H. (1993) “"Going Bonkers!": Children, play and Pee-wee’ in C. Penly \& S.

Willis (eds.) Male Trouble (Minneapolis, MN: University of Minnesota Press).

Knapp M., \& Knapp H. (1976) One potato, two potato: The secret education of American children (New York, NY: W.W. Norton).

Kristeva J. (1991) Strangers to ourselves (New York, NY: Columbia University Press).

MacEinri P. (1994) 'How does it feel? Migrants and the postmodern condition'. Chimera, 87-94.

Mohanty C. T. (2003) Feminism without borders: Decolonizing theory, practicing solidarity (London, UK: Duke University Press).

Peters M. A., \& Marshall J.D. (1996) Individualism and community: Education and social policy in the postmodern condition (London, UK: Falmer Press).

Rose G. (1995) 'Place and identity: A sense of place' in D. Massey \& P. Jess (eds.) A place in the world? Places, cultures and globalization (Oxford, UK: The Open University).

Silva K. (2009) 'Oh, give me a home: diasporic longings of home and belonging', Social Identities, 15(5), 693-706.

Sturm B. W. (2008) 'Imaginary "geographies" of childhood: School library media centers as secret spaces', Knowledge Quest, 36(4), 46-53.

Swanson K. (2010) "'For every border, there is also a bridge": Overturning borders in young Aboriginal peoples' lives', Children's Geographies, 8(4), 429-436.

Tietz E. (2009) 'Losing home and hearth' in H. Blaich (ed.) Exiled from the Holy Land (Melbourne, Australia: Temple Society Australia Heritage Group). 
Todd S. (2004) 'Teaching with ignorance: Questions of social justice, empathy, and responsible community', Interchange, 35(3), 337-352.

Tucker E. (1995) 'Tales and legends' in B. Sutton-Smith, J. Mechling, T. W. Johnson \& F. R. McMahon (eds.) Children's folklore: A source book (New York, NY: Garland Publishing).

Van Manen M., \& Levering B. (1996) Childhood's secrets: Intimacy, privacy, and the self reconsidered (New York, NY: Teachers College Press).

Wise J. M. (2000) 'Home: Territory and identity', Cultural Studies, 14(2), 295-310.

Zipes J. D. (2006) Fairy tales and the art of subversion (New York, NY: Taylor \& Francis). 